\title{
Early life exposure to antibiotics and the subsequent development of eczema, wheeze, and allergic sensitization in the first 2 years of life: the KOALA Birth Cohort Study
}

Citation for published version (APA):

Kummeling, I., Stelma, F. F., Dagnelie, P. C., Snijders, B. E., Penders, J., Huber, M., Van Ree, R., van den Brandt, P. A., \& Thijs, C. (2007). Early life exposure to antibiotics and the subsequent development of eczema, wheeze, and allergic sensitization in the first 2 years of life: the KOALA Birth Cohort Study. Pediatrics, 119(1), e225-231. https://doi.org/10.1542/peds.2006-0896

Document status and date:

Published: 01/01/2007

DOI:

10.1542/peds.2006-0896

Document Version:

Publisher's PDF, also known as Version of record

Please check the document version of this publication:

- A submitted manuscript is the version of the article upon submission and before peer-review. There can be important differences between the submitted version and the official published version of record. People interested in the research are advised to contact the author for the final version of the publication, or visit the DOI to the publisher's website.

- The final author version and the galley proof are versions of the publication after peer review.

- The final published version features the final layout of the paper including the volume, issue and page numbers.

Link to publication

\footnotetext{
General rights rights.

- You may freely distribute the URL identifying the publication in the public portal. please follow below link for the End User Agreement:

www.umlib.nl/taverne-license

Take down policy

If you believe that this document breaches copyright please contact us at:

repository@maastrichtuniversity.nl

providing details and we will investigate your claim.
}

Copyright and moral rights for the publications made accessible in the public portal are retained by the authors and/or other copyright owners and it is a condition of accessing publications that users recognise and abide by the legal requirements associated with these

- Users may download and print one copy of any publication from the public portal for the purpose of private study or research.

- You may not further distribute the material or use it for any profit-making activity or commercial gain

If the publication is distributed under the terms of Article $25 \mathrm{fa}$ of the Dutch Copyright Act, indicated by the "Taverne" license above, 


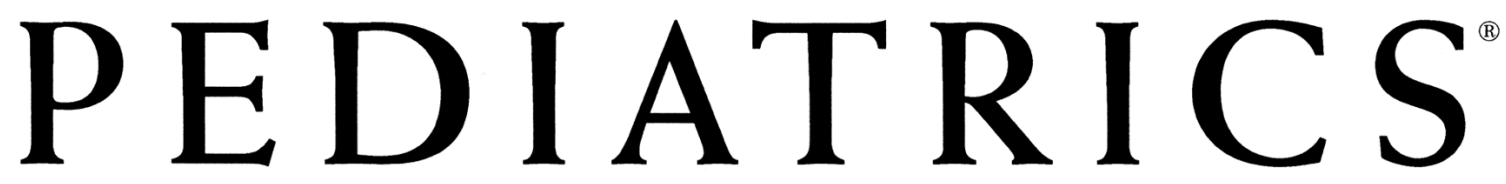

OFFICIAL JOURNAL OF THE AMERICAN ACADEMY OF PEDIATRICS

Early Life Exposure to Antibiotics and the Subsequent Development of Eczema, Wheeze, and Allergic Sensitization in the First 2 Years of Life: The KOALA Birth Cohort Study

Ischa Kummeling, Foekje F. Stelma, Pieter C. Dagnelie, Bianca E. P. Snijders, John Penders, Machteld Huber, Ronald van Ree, Piet A. van den Brandt and Carel Thijs Pediatrics 2007;119; 225-e231

DOI: $10.1542 /$ peds.2006-0896

The online version of this article, along with updated information and services, is located on the World Wide Web at: http://www.pediatrics.org/cgi/content/full/119/1/e225

PEDIATRICS is the official journal of the American Academy of Pediatrics. A monthly publication, it has been published continuously since 1948. PEDIATRICS is owned, published, and trademarked by the American Academy of Pediatrics, 141 Northwest Point Boulevard, Elk Grove Village, Illinois, 60007. Copyright ( 2007 by the American Academy of Pediatrics. All rights reserved. Print ISSN: 0031-4005. Online ISSN: 1098-4275.

\section{American Academy of Pediatrics}

DEDICATED TO THE HEALTH OF ALL CHILDREN ${ }^{m}$ 


\title{
Early Life Exposure to Antibiotics and the Subsequent Development of Eczema, Wheeze, and Allergic Sensitization in the First 2 Years of Life: The KOALA Birth Cohort Study
}

\author{
Ischa Kummeling, MSca, Foekje F. Stelma, MDa,b, Pieter C. Dagnelie, PhDc, Bianca E. P. Snijders ${ }^{a}$, John Penders, MSca, Machteld Huber, MD ${ }^{d}$, \\ Ronald van Ree, PhDe, Piet A. van den Brandt, PhDa, Carel Thijs, MDa,c \\ aDepartment of Epidemiology, Care and Public Health Research Institute, and cDepartment of Epidemiology, Nutrition and Toxicology Research Institute, Maastricht \\ University, Maastricht, Netherlands; bDepartment of Medical Microbiology, University Hospital of Maastricht, Maastricht, Netherlands; ' Louis Bolk Institute, Driebergen, \\ Netherlands; eDepartment of Experimental Immunology, Academic Medical Center, Amsterdam, Netherlands
}

The authors have indicated they have no financial relationships relevant to this article to disclose.

\section{ABSTRACT}

OBJECTIVES. Antibiotic exposure in early life may be associated with atopic disease development either by interfering with bacterial commensal flora or by modifying the course of bacterial infections. We evaluated early life exposure to antibiotics and the subsequent development of eczema, wheeze, and allergic sensitization in infancy.

METHODS. Information on antibiotic use in the first 6 months and eczema and wheeze until age 2 was collected by repeated questionnaires in 2764 families participating in the KOALA (Child, Parent and Health: Lifestyle and Genetic Constitution [in Dutch]) Birth Cohort Study in the Netherlands. Antibiotic intake was evaluated both as maternal antibiotic use during breastfeeding and infant oral medication. Venous blood samples taken from 815 infants at 2 years of age were analyzed for total and specific immunoglobulin $\mathrm{E}$ against common food and inhalant allergens using a radioallergosorbent test. Multivariate logistic regression analysis was used to adjust for confounding factors.

RESULTS. During the first 2 years, eczema was present in $32 \%$ of all infants, recurrent wheeze in $11 \%$, and prolonged wheezing in $5 \%$. At 2 years old, $27 \%$ of children were sensitized against $\geq 1$ allergen. At 6 months old, $11 \%$ had been exposed to antibiotics through breast milk and $20 \%$ directly through medication. The risk for recurrent wheeze, and prolonged wheeze was higher in infants directly exposed to antibiotics through medication, also after excluding from the analyses children who wheezed in the same period as an antibiotic had been used (avoiding reverse causation). Antibiotic use through breastfeeding was associated with recurrent wheeze, but prolonged wheeze was not. Eczema and sensitization were not associated with antibiotic exposure.

www.pediatrics.org/cgi/doi/10.1542/
peds.2006-0896
doi:10.1542/peds.2006-0896
Key Words
antibiotics, infants, eczema, wheeze,
allergic sensitization
Abbreviations
PPGP_-pregnancy-related pelvic girdle
pain
KOALA—Child, Parent and Health: Lifestyle
and Genetic Constitution (in Dutch)
IgE-immunoglobulin E
ETS-environmental tobacco smoke
RAST-radioallergosorbent test
OR-odds ratio
CI-confidence interval
Accepted for publication Jul 17, 2006
Address correspondence to Ischa Kummeling,
MSc, Department of Epidemiology, Maastricht
University, PO Box 616, 6200 MD, Maastricht,
Netherlands. E-mail: Ischa.Kummeling@epid.
unimaas.nl
PEDIATRICS (ISSN Numbers: Print, 0031-4005;
Online, 1098-4275). Copyright 02007 by the
American Academy of Pediatrics

www.pediatrics.org/cgi/doi/10.1542/ peds.2006-0896

Key Words allergic sensitization

Abbreviations and Genetic Constitution (in Dutch)

OR — odds ratio

MSc, Department of Epideminlogy, Mastrich University, PO Box 616, 6200 MD, Maastricht, Netherlands. E-mail: Ischa.Kummeling@epid. American Academy of Pediatric 
CONCLUSIONS. We demonstrated that early antibiotic use preceded the manifestation of wheeze but not eczema or allergic sensitization during the first 2 years of life. Different biological mechanisms may underlie the etiology of wheeze compared with eczema or sensitization. Antibiotic exposure through breastfeeding enhanced the risk for recurrent wheeze, but this needs further confirmation.

$\mathrm{T}$ HE PREVALENCE OF atopic manifestations, which include atopic eczema, allergic rhinoconjunctivitis, and asthma, have increased worldwide, especially in children. ${ }^{1,2}$ Symptoms are most common in western countries but also increase in developing countries as they become more westernized. Currently one third of the children in western societies show symptoms. ${ }^{3}$

Many western lifestyle and medical care characteristics have changed over the years and might be of interest in relation to atopy. For example, the increased pediatric allergy in developed countries closely followed time trends in increased use of antibiotics among young children. Antibiotics particularly interfere with the bacterial commensal flora and disturb the intestinal microbiota composition. ${ }^{4,5}$ It has been hypothesized that infections in early life, as well as colonization of the gut, protects against atopy. ${ }^{6}$ Consequently, antibiotic exposure in early life may be associated with atopic disease development either by interfering with bacterial commensal flora or by modifying the course of bacterial infections.

Indeed, positive associations between antibiotic use and childhood allergy and asthma have been reported. ${ }^{7-14}$ The majority of these results came from crosssectional studies, and, in many, , ,8,10-12,14 the question of "reverse causation" remained unresolved: Did antibiotic intake precede symptoms or were antibiotics prescribed in response to symptoms of wheezy bronchitis? Also, evaluation of exposure to antibiotics through breastfeeding and subsequent development of atopy is lacking. Antibiotic use is fairly common among breastfeeding mothers, ${ }^{15}$ in particular, penicillins, for the treatment of mastitis. Both have been detected in breast milk in small quantities, as reviewed by Chung et al. ${ }^{16}$ Maternal use of antibiotics is relevant with regard to transfer to the breastfed infant.

In a large prospective birth cohort study in the Netherlands, we prospectively evaluated the association between early life antibiotic exposure, both through maternal antibiotic use during breastfeeding and through infant oral medication, and the subsequent development of eczema, wheeze, and allergic sensitization in the first 2 years of life.

\section{METHODS}

\section{Study Subjects}

A detailed description of the design of our cohort has been published previously. ${ }^{17}$ In summary, the KOALA
(Child, Parent and Health: Lifestyle and Genetic Constitution [in Dutch]) Birth Cohort Study started in October 2000. Participants were recruited in the southern half of the Netherlands from 2 sources. First, pregnant women were recruited from an ongoing prospective cohort study on pregnancy-related pelvic girdle pain (PPGP).18 Participants of the PPGP study were recruited via midwife clinics at 14 to 16 weeks of gestation. At 34 weeks of gestation, PPGP subjects were asked to participate in the KOALA Study ("conventional subcohort"). Second, to increase the number of participants with lifestyle choices that have a low prevalence in the general population, pregnant women with so-called "alternative" lifestyles were recruited through several specific recruitment channels, that is, anthroposophic doctors and midwives, anthroposophic under-5 clinics, Steiner Schools, posters and flyers in organic food shops, and magazines for special interest groups (eg, homeopathy, anthroposophy, and antivaccine; "alternative subcohort"). These women were enrolled at 14 to 18 weeks of gestation. A total of 2834 participants were included in the KOALA Study, of whom 2343 were through the PPGP study and 491 through the specific recruitment channels. The study was approved by the Medical Ethical Committee of University Maastricht/Academic Hospital Maastricht. All of the participants had signed informed consent and completed the first questionnaire at the third trimester of pregnancy. Most parents (96\%) were white Dutch.

Exclusion criteria in the present study were prematurity (gestational age $<37$ weeks) and congenital abnormalities related to immunity (such as Down syndrome). Three children were excluded for Down syndrome and 67 for prematurity, resulting in 2764 participants. Of these, follow-up data were available for $93.4 \%(n=2598)$, which was $93.5 \%(n=2135)$ of the conventional and $96.3 \%(n=463)$ of the alternative subcohort.

From January 2004, additional funding was obtained, and parents who were part of the second half of the cohort $(n=1301)$ were also asked to consent to collecting venous blood from their infant at age 2 years (for the determination of total and allergen-specific IgE-levels). Of these, $815(65 \%)$ signed informed consent and were visited at home for blood sampling.

\section{Exposure and Follow-up}

All of the parents were sent detailed questionnaires when the infants were 3, 7, 12, and 24 months of age. Variables considered for inclusion in the multivariate analysis were participant's characteristics, such as the infant's gender, parental and siblings' atopic history, and number of older siblings. Positive parental atopic history was defined as $\geq 1$ self-reported doctor's diagnoses of asthma, pet or house dust mite allergy, hay fever, and eczema (none, father, mother, or both). Sibship size and siblings history of atopy (parental reports of doctor's 
diagnosed asthma, pet or house dust mite allergy, hay fever, eczema, and/or food allergy) were combined (no siblings; 1 sibling, not atopic; 1 sibling, atopic; $\geq 2$ siblings, not atopic; and $\geq 2$ siblings, $\geq 1$ atopic). Other factors included place and mode of delivery (natural delivery at home, natural delivery in hospital, artificial delivery in hospital [eg, delivery by vacuum or forceps extraction], or cesarean section in hospital), breastfeeding at 6 months of age (breastfeeding at 6 months old that was exclusive at months $1-4$; breastfeeding at 6 months old that was nonexclusive at months 1-4; no breastfeeding at 6 months old but exclusive breastfeeding at months 1-4; no breastfeeding at 6 months old but nonexclusive breastfeeding at months $1-4$; or never breastfeeding), attending day care facilities in the first 6 months (yes/no), any furred pets in the first 6 months (yes/no), exposure to environmental tobacco smoke (ETS) in the first 6 months (yes/no), and experiencing a period of fever (body temperature $>38^{\circ} \mathrm{C}$ ) during the first 6 months (yes/no). Parents were asked whether their child had been vaccinated according to the standard scheme, an "alternative vaccination scheme," or not at all. In the Netherlands during the time of the study, infants in their first 6 months were standard vaccinated against diphtheria, tetanus, pertussis (with whole-cell pertussis vaccine), poliomyelitis, and Haemophilus influenzae type B vaccine at 2, 3, and 4 months of age. An alternative vaccination scheme was defined as delayed vaccinations or alternative vaccine composition (eg, omitting the pertussis component from the diphtheria-pertussis-tetanus-polio vaccine).

Antibiotic use in the first 6 months postpartum was assessed by questionnaires. Mothers were asked whether they had used antibiotics during lactation and whether they had completed the course. Antibiotic exposure through breast milk was classified positively if a mother completed a course of antibiotic treatment during lactation. Parents were also asked whether their child had used antibiotics and, if yes, for how many days. Direct oral antibiotic exposure was defined as positive when the child had ever been given oral antibiotics for $>3$ consecutive days. No distinction was made between different antibiotics or multiple courses of antibiotics versus a single course in the questionnaire.

Eczema and wheeze occurrence were assessed by questionnaires. At age 7, 12, and 24 months, parents were asked whether their child had ever had an itchy rash that was coming and going in the past months. If this question was answered affirmatively at least once, infants were classified as having developed eczema in the first 2 years of life. Infants for whom only diaper rash, rash around the eyes, and/or scalp scaling was reported were not regarded as having developed eczema. Wheeze was also asked in the 7-, 12-, and 24-month postpartum questionnaires. "Recurrent wheeze" was defined as reported presence of wheezing with $\geq 4$ attacks ever in the first 2 years. "Prolonged wheeze" was classified as ever been awake because of wheezing in both the first and second year.

\section{Assessment of Sensitization}

Total IgE antibodies were measured by radioimmunoassay in serum samples as described earlier. ${ }^{19,20}$ Results were expressed as international units of IgE per milliliter; $1 \mathrm{IU}$ is $2.4 \mathrm{ng}$ of $\mathrm{IgE}$. For values $<150 \mathrm{IU} / \mathrm{mL}$, a sandwich radioimmunoassay was used, ${ }^{19}$ and for values $>150 \mathrm{IU} / \mathrm{mL}$, a competitive radioimmunoassay was used. ${ }^{20}$ Serum level of hen's egg-, cow's milk-, peanut-, birch-, grass pollen-, cat-, dog-, and mite-specific IgE was determined by radioallergosorbent test (RAST) as described previously. ${ }^{20}$ Calculation was performed by means of a standard curve that was obtained by RAST with a dilution series of a chimeric monoclonal IgE antibody against the major house dust mite allergen Der $\mathrm{p}$ 2 and Sepharose-coupled recombinant Der p 2. ${ }^{21}$ The detection limit for total and specific IgE was $<0.50$ $\mathrm{IU} / \mathrm{mL}$ and $<0.13 \mathrm{IU} / \mathrm{mL}$, respectively. We defined allergic sensitization as a RAST value $>0.3 \mathrm{IU} / \mathrm{mL}$ for $\geq 1$ allergen and high allergic sensitization when the value was $>0.7 \mathrm{IU} / \mathrm{mL}$.

\section{Statistical Analysis}

The relationship between antibiotic exposure and atopic manifestations was evaluated in participants with complete information on $\geq 1$ of the atopic manifestations. Missing data in the questionnaires were treated as missing in the analyses and are presented as "unknown" in the tables. Unadjusted associations between antibiotic exposure and atopic outcomes were examined using logistic regression. Multivariate logistic regression models were used to control for potential confounders (gender, parental history of allergy, sibling history of allergy, number of older siblings, place and mode of delivery, breastfeeding, day care attendance, pets, exposure to ETS, vaccinations, and subcohort) by including them in the regression models simultaneously. Differences in mean total IgE levels were evaluated by means of linear regression analyses controlling for the same confounders. Analyses for determination of the effect of antibiotics through breast milk were controlled for the potential confounding effect of antibiotic exposure through oral medication and vice versa. Some previous studies reported associations between exposures and atopic outcomes to be limited to groups with different inherited propensity for developing atopic disease. ${ }^{22,23}$ In the multivariate analysis, therefore, we first tested the possibility of interaction between antibiotic use and parental history of atopy. Because none of these interaction terms were statistically significant, they were eliminated from the regression models. Separate analyses of the conventional versus alternative subcohort or boys versus girls showed that the key findings were similar within these 


\begin{tabular}{|c|c|c|}
\hline \multirow[t]{2}{*}{ Characteristic } & \multicolumn{2}{|c|}{ Total Cohort } \\
\hline & $n$ & $\%^{\mathrm{a}}$ \\
\hline$\overline{\text { Male }}$ & 1410 & 51 \\
\hline \multicolumn{3}{|l|}{ Parental history of allergy } \\
\hline None & 1339 & 48 \\
\hline Father & 519 & 19 \\
\hline Mother & 604 & 22 \\
\hline Both & 302 & 11 \\
\hline \multicolumn{3}{|l|}{ Sibling history of allergy } \\
\hline No siblings & 1155 & 44 \\
\hline 1 sibling, not atopic & 833 & 31 \\
\hline 1 sibling, atopic & 261 & 10 \\
\hline$\geq 2$ siblings, not atopic & 235 & 9 \\
\hline$\geq 2$ siblings, 1 or both atopic & 159 & 6 \\
\hline Unknown & 121 & \\
\hline \multicolumn{3}{|l|}{ Place and mode of delivery } \\
\hline Natural delivery at home & 1179 & 46 \\
\hline Natural delivery in hospital & 891 & 34 \\
\hline Artificial delivery in hospital & 217 & 8 \\
\hline Cesarean section in hospital & 296 & 12 \\
\hline Unknown & 181 & \\
\hline \multicolumn{3}{|l|}{ BF at 6 mo old } \\
\hline Yes, months 1-4 exclusive BF & 622 & 25 \\
\hline Yes, months 1-4 nonexclusive BF & 441 & 17 \\
\hline No, months 1-4 exclusive BF & 62 & 3 \\
\hline No, months $1-4$ nonexclusive & 996 & 39 \\
\hline Never BF & 410 & 16 \\
\hline Unknown & 233 & \\
\hline \multicolumn{3}{|l|}{ Day care in first 6 mo } \\
\hline Yes & 831 & 32 \\
\hline No & 1724 & 68 \\
\hline Unknown & 209 & \\
\hline \multicolumn{3}{|l|}{ Pets in first 6 mo } \\
\hline Yes & 1168 & 45 \\
\hline No & 1387 & 54 \\
\hline Unknown & 209 & \\
\hline \multicolumn{3}{|l|}{ Exposure to ETS in first 6 mo } \\
\hline Yes & 294 & 12 \\
\hline No & 2197 & 88 \\
\hline Unknown & 273 & \\
\hline \multicolumn{3}{|l|}{ Vaccinations in first 6 mo } \\
\hline By standard scheme & 2242 & 88 \\
\hline By alternative scheme ${ }^{b}$ & 115 & 4 \\
\hline None & 188 & 8 \\
\hline Unknown & 219 & \\
\hline \multicolumn{3}{|l|}{$\begin{array}{l}\text { Antibiotic exposure through BF in } \\
\text { first } 6 \text { mo }\end{array}$} \\
\hline Yes & 262 & 10 \\
\hline No & 2161 & 90 \\
\hline Unknown & 341 & \\
\hline \multicolumn{3}{|c|}{$\begin{array}{l}\text { Antibiotic exposure through oral medication } \\
\text { in first } 6 \text { mo }\end{array}$} \\
\hline Yes & 489 & 20 \\
\hline No & 1973 & 80 \\
\hline Unknown & 302 & \\
\hline \multicolumn{3}{|l|}{ Eczema in first $2 y$} \\
\hline Yes & 817 & 32 \\
\hline No & 1766 & 68 \\
\hline Unknown & 181 & \\
\hline \multicolumn{3}{|l|}{ Recurrent wheeze in first $2 y$} \\
\hline Yes & 265 & 11 \\
\hline No & 2077 & 89 \\
\hline Unknown & 422 & \\
\hline
\end{tabular}

TABLE 1 Continued

\begin{tabular}{lrr}
\hline \multirow{2}{*}{ Characteristic } & \multicolumn{2}{c}{ Total Cohort } \\
\cline { 2 - 3 } & $n$ & $\%^{\text {a }}$ \\
\hline Prolonged wheeze in first 2y & 137 & 5 \\
Yes & 2409 & 95 \\
No & 218 & \\
Unknown & & \\
Allergic sensitisation at age 2yc & 223 & 27 \\
Yes & 592 & 72 \\
No & & \\
Specific lgE against: & 48 & 6 \\
Hen's egg & 153 & 19 \\
Cow's milk & 42 & 5 \\
Peanut & 7 & 1 \\
Birch & 13 & 2 \\
Grass pollen & 25 & 3 \\
Cat & 15 & 2 \\
Dog & 52 & 6 \\
Mite & & \\
\hline
\end{tabular}

BF indicates breastfeeding.

a Excluding missing data.

b Delayed scheme or alternative composition of vaccine.

cAnalyses conducted among infants with blood sample $(n=815)$. "Allergic sensitisation" refers to $\geq 1$ allergen-specific $\lg E \geq 0.3 \mathrm{IU} / \mathrm{mL}$.

groups. Therefore, we combined all of the infants in the final analyses, adjusting for "subcohort" and "gender." Results are presented as unadjusted and adjusted odds ratios (ORs) with corresponding 95\% confidence intervals (CIs).

\section{RESULTS}

\section{Study Subjects}

Approximately half of infants had nonatopic parents; one third had 1 nonatopic older sibling, and $10 \%$ had 1 atopic older sibling (Table 1). Most traditional risk factors were equally present in both subcohorts, but in the alternative subcohort, antibiotic exposure through medication was less present than in the conventional subcohort. Prevalence of baseline characteristics and eczema and wheeze manifestations did not differ between infants with and without blood samples. By the age of 6 months, $262(11 \%)$ of 2423 infants had been exposed to antibiotics through breastfeeding and $489(20 \%)$ of 2462 infants through oral medication.

\section{Eczema, Wheeze, and Sensitization by Antibiotic Exposure}

In total, $817(32 \%)$ of 2583 infants were classified as having had eczema in the first 2 years of life (this was $32 \%$ in the conventional and $30 \%$ in the alternative subcohort). The incidence of recurrent wheeze was 265 (11\%) of 2342 infants (12\% in the conventional and 6\% in the alternative subcohort). In total, for $137(5 \%)$ of 2546 infants, parents reported prolonged wheezing $(6 \%$ in the conventional and $4 \%$ in the alternative subcohort). Of infants with reported wheeze in the first 2 years, $70 \%$ had used $\beta 2$-adrenergic or steroid inhalant 
therapy at least once. Of infants with blood samples, 223 $(27 \%)$ were sensitized against $\geq 1$ allergen at 2 years old (29\% in the conventional and $24 \%$ in the alternative subcohort).

The associations for antibiotic exposure through breastfeeding and through medication were independent from each other (because both were included in the logistic regression models simultaneously). Antibiotic exposure either through breastfeeding or directly through medication was not associated with eczema (Table 2). However, antibiotic exposure through breastfeeding was associated with a higher risk of recurrent wheeze (adjusted OR: 1.55; 95\% CI: 1.02-2.37). This was not found for prolonged wheeze (adjusted OR: 1.12; 95\% CI: 0.62-2.02). Antibiotic exposure through medication was associated with an elevated risk for recurrent wheeze (adjusted OR: 2.65; 95\% CI: 1.95-3.60) and prolonged wheeze (adjusted OR: 2.32; 95\% CI: 1.553.48).

There was no association between antibiotic exposure through breastfeeding and allergic sensitization or between antibiotic medication and allergic sensitization (Table 2). This result remained unchanged when using a lower cutoff point for sensitization (specific IgE $>0.13$ $\mathrm{IU} / \mathrm{mL}$ ) or when sensitization to $\geq 2$ allergens was considered as the outcome (data not shown). Mean total serum IgE level at 2 years old was not different between infants with and without antibiotic exposure either through breastfeeding $(\beta=.002 ; P=.99)$ or medication $(\beta=.048 ; P=.80)$.

To exclude potential reverse causation in the association between antibiotic exposure and wheeze, we excluded from the analyses children who wheezed in the first half year of life ( $n=203$ for recurrent wheeze; $n=$ 436 for prolonged wheeze). The ORs for wheezing did not change much compared with those in Table 2 (adjusted OR for recurrent wheezing: 2.18 ; $95 \%$ CI: $1.46-$ 3.25; adjusted OR for prolonged wheezing: 2.39; $95 \%$ CI: $1.50-3.81)$. If we restricted our analysis to infants who had been breastfed, the association between antibiotic exposure through breastfeeding and recurrent wheeze remained unchanged (adjusted OR: 1.54; 95\% CI: $1.01-2.36)$.

For all outcomes, we tested the possibility of interaction between antibiotic exposure and a parental history of atopic manifestations in the multivariate analyses. None of the tests for interaction showed a statistically significant interaction ( $P$ always $\geq 0.10$ ).

\section{DISCUSSION}

This prospective study shows that early antibiotic exposure, both indirect through breastfeeding and direct through oral medication, is associated with the subsequent development of wheezing in the first 2 years of life. No association was found between antibiotic exposure and eczema or allergic sensitization. To our knowl-

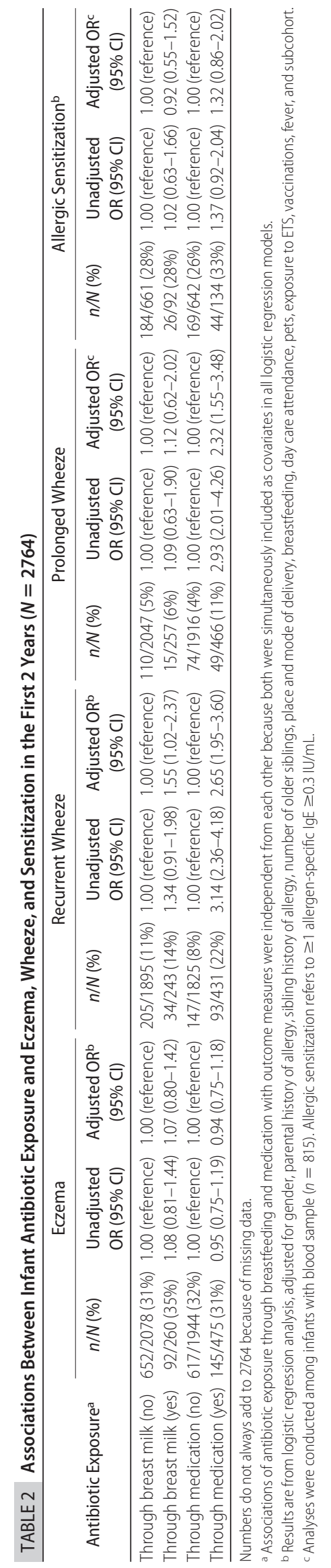


edge, this is the first study focusing on the association between antibiotic exposure through breastfeeding and the development of atopy. Our study has the advantage of being population-based, with relatively short intervals between subsequent follow-up questionnaires, which decreases the possibility of recall bias. Follow-up rates were high, which limited differential bias with regard to baseline characteristics or outcomes.

Atopic outcomes, like infant eczema and wheeze, may be fairly unspecific for infants aged 2 years $^{24}$ and, therefore, weak indicators of atopic development, such as asthma in children. Children with physician-confirmed wheeze have been reported to have significantly poorer lung function compared with those with only parentally reported wheeze that was medically unconfirmed. ${ }^{25}$ In individuals with an atopic constitution, the underlying mechanism of developing eczema is often dominated by an IgE antibody-associated reaction to specific allergens, justifying the term "atopic eczema." Specific IgE or total serum IgE levels are, however, only weakly associated with atopic symptoms, like eczema and wheeze. ${ }^{26}$ Therefore, we evaluated clinical symptoms and allergic sensitization as separate outcomes and used the term eczema instead of atopic eczema. Our definition of eczema was based on questions adapted from the International Study of Asthma and Allergies in Childhood questionnaires and included generally accepted characteristics, like a chronically relapsing course and an itchy rash. Our definition of recurrent wheeze was also based on International Study of Asthma and Allergies in Childhood questionnaires. In addition, we identified a second more stringent definition of wheeze ("prolonged"), restricting it to being awake because of wheezing in both the first and second year. In contrast to most population-based studies, we chose to rely on parents "reported symptoms" more than "doctor's diagnosis" when defining outcome variables to avoid bias because of the increased likelihood of getting a doctor's diagnosis of asthma when parents consult a doctor for the infant's wheezing and get antibiotic medication (at the same or a different occasion). In addition, parents were asked whether medical care was provided to the wheezing infant. This was true for $70 \%$ of wheezy infants, which reinforced us to rely on the parental reports of wheezing. Lacking information on the antibacterial spectrum (broad versus narrow), specific indication for which the antibiotics had been prescribed, or multiple courses of antibiotics versus a single course represents a limitation in our study.

Two questions arise from our findings. First, why was antibiotic use associated with wheeze but not eczema and allergic sensitization? Second, what are the possible mechanisms by which antibiotic exposure increases the risk of wheeze in infancy? We found that wheeze was associated with antibiotic use, but eczema and sensitization were not, and exposure through breastfeeding was associated only with recurrent wheeze. This finding contradicts the finding that antibiotics have a direct influence on the maturating immune system or affect the development of atopic disease by preventing invasive bacterial infections (if so, eczema and sensitization would also be affected). The exclusive association between antibiotic use and the development of wheeze may be because of reverse causation. It is likely that antibiotics are prescribed because of wheezy bronchitis and related conditions; however, this is unlikely when considering eczema and allergic sensitization. To eliminate the possibility of reverse causation, we excluded from the analysis those infants who wheezed in the same period (interval between questionnaires) as antibiotic medication had been used, thereby avoiding the fact that symptoms preceded antibiotic prescription.

However, the association between antibiotic exposure through breastfeeding and wheeze constitutes an argument against reverse causation. Antibiotics administrated to the infant through breastfeeding are prescribed independently of any infant disease, because the indication is a maternal infectious episode. Two possible biological mechanisms may explain why wheeze was more susceptible to antibiotic use than the other 2 outcome measures, eczema and sensitization. Because of a difficult differential diagnosis in general practice between bacterial and viral infections, antibiotics in infancy are often prescribed for viral infections. ${ }^{27}$ Respiratory syncytial virus and rhinovirus infections are strongly associated with infant wheeze in the first years of life, ${ }^{28}$ and antibiotic use may simply be a marker for viral infections. This may only apply to young infants, because the prospective birth cohort study of Celedon et al ${ }^{29}$ did not show an association between antibiotic use in the first year and wheeze in 5-year-old children.

Also, antibiotics may compromise the commensal flora of the upper airways, ${ }^{30}$ thereby making way for viral infections, some of which may cause later wheeze. Simultaneously this explains why antibiotic exposure through breastfeeding is more associated with recurrent wheeze than prolonged wheeze. When the infant is being compromised by maternal antibiotic use, the commensal flora of the upper airways of the infant will recover only after the mother ceases her antibiotic course. The definition of prolonged wheeze symptoms is the presence of wheeze in the first and second year of infant life. It is according to the expectation that there is no association between antibiotic use and prolonged wheeze, because it is unlikely that mothers still breastfed in the second year of life.

Our finding that antibiotic exposure was not associated with eczema is in agreement with previous cohort studies, ${ }^{29,31}$ whereas some cross-sectional studies showed positive associations. ${ }^{7-10}$ Cross-sectional studies must be interpreted with caution. They may be subject to differential recall bias, and recall of antibiotic use may be 
linked to the reporting of atopic manifestations (reporting bias). Furthermore our study confirms previous results that antibiotic use was not associated with allergic sensitization at age 2 years. ${ }^{29}$

Taken together, we demonstrated that early antibiotic use preceded the manifestation of wheeze but not eczema or allergic sensitization during the first 2 years of life. Different biological mechanisms may underlie the etiology of wheeze compared with eczema or sensitization. The effect of antibiotic use through breastfeeding on wheeze was small (OR: $<2$ ), and until further research has been performed, we recommend that this finding is replicated in other prospective studies.

\section{REFERENCES}

1. Maziak W, Behrens T, Brasky TM, et al. Are asthma and allergies in children and adolescents increasing? Results from ISAAC phase I and phase III surveys in Munster, Germany. Allergy. 2003;58:572-579

2. Beasley R, Crane J, Lai CK, Pearce N. Prevalence and etiology of asthma. J Allergy Clin Immunol. 2000;105:S466-S472

3. The International Study of Asthma and Allergies in Childhood (ISAAC) Steering Committee. Worldwide variation in prevalence of symptoms of asthma, allergic rhinoconjunctivitis, and atopic eczema: ISAAC. Lancet. 1998;351:1225-1232

4. Levy J. The effects of antibiotic use on gastrointestinal function. Am J Gastroenterol. 2000;95:S8-S10

5. Brismar B, Edlund C, Nord CE. Impact of cefpodoxime proxetil and amoxicillin on the normal oral and intestinal microflora. Eur J Clin Microbiol Infect Dis. 1993;12:714-719

6. Bjorksten B, Naaber P, Sepp E, Mikelsaar M. The intestinal microflora in allergic Estonian and Swedish 2-year-old children. Clin Exp Allergy. 1999;29:342-346

7. Floistrup H, Swartz J, Bergstrom A, et al. Allergic disease and sensitization in Steiner school children. J Allergy Clin Immunol. 2006;1 17:59-66

8. Wjst M, Hoelscher B, Frye C, Wichmann HE, Dold S, Heinrich J. Early antibiotic treatment and later asthma. Eur J Med Res. 2001;6:263-271

9. Droste JH, Wieringa MH, Weyler JJ, Nelen VJ, Vermeire PA, Van Bever HP. Does the use of antibiotics in early childhood increase the risk of asthma and allergic disease? Clin Exp Allergy. 2000;30:1547-1553

10. von Mutius E, Illi S, Hirsch T, Leupold W, Keil U, Weiland SK. Frequency of infections and risk of asthma, atopy and airway hyperresponsiveness in children. Eur Respir J. 1999;14:4-11

11. Wickens K, Pearce N, Crane J, Beasley R. Antibiotic use in early childhood and the development of asthma. Clin Exp Allergy. 1999;29:766-771

12. Alm JS, Swartz J, Lilja G, Scheynius A, Pershagen G. Atopy in children of families with an anthroposophic lifestyle. Lancet. 1999;353:1485-1488

13. Farooqi IS, Hopkin JM. Early childhood infection and atopic disorder. Thorax. 1998;53:927-932

14. Cohet C, Cheng S, MacDonald C, et al. Infections, medication use, and the prevalence of symptoms of asthma, rhinitis, and eczema in childhood. J Epidemiol Community Health. 2004;58: 852-857

15. Mathew JL. Effect of maternal antibiotics on breast feeding infants. Postgrad Med J. 2004;80:196-200

16. Chung AM, Reed MD, Blumer JL. Antibiotics and breastfeeding: a critical review of the literature. Paediatr Drugs. 2002; 4:817-837

17. Kummeling I, Thijs C, Penders J, et al. Etiology of atopy in infancy: the KOALA Birth Cohort Study. Pediatr Allergy Immunol. 2005;16:679-684

18. Bastiaanssen JM, de Bie RA, Bastiaenen CH, et al. Etiology and prognosis of pregnancy-related pelvic girdle pain; design of a longitudinal study. BMC Public Health. 2005;5:1-8

19. Stallman PJ, Aalberse RC. Estimation of basophil-bound IgE by quantitative immunofluorescence microscopy. Int Arch Allergy Appl Immunol. 1977;54:9-18

20. Akkerdaas JH, Wensing $M$, Asero $\mathrm{R}$, et al. IgE binding to pepsin-digested food extracts. Int Arch Allergy Immunol. 2005; 138:203-208

21. Schuurman J, Perdok GJ, Lourens TE, et al. Production of a mouse/human chimeric IgE monoclonal antibody to the house dust mite allergen Der p 2 and its use for the absolute quantification of allergen-specific IgE. J Allergy Clin Immunol. 1997; 99:545-550

22. Remes ST, Castro Rodriguez JA, Holberg CJ, Martinez FD, Wright AL. Dog exposure in infancy decreases the subsequent risk of frequent wheeze but not of atopy. J Allergy Clin Immunol. 2001;108:509-515

23. Wright AL, Sherrill D, Holberg CJ, Halonen M, Martinez FD. Breast-feeding, maternal IgE, and total serum IgE in childhood. J Allergy Clin Immunol. 1999;104:589-594

24. Koopman LP, Brunekreef B, de Jongste JC, Neijens HJ. Definition of respiratory symptoms and disease in early childhood in large prospective birth cohort studies that predict the development of asthma. Pediatr Allergy Immunol. 2001;12:118-124

25. Lowe L, Murray CS, Martin L, et al. Reported versus confirmed wheeze and lung function in early life. Arch Dis Child. 2004;89: 540-543

26. Kusel MM, Holt PG, de Klerk N, Sly PD. Support for 2 variants of eczema. J Allergy Clin Immunol. 2005; 1 16:1067-1072

27. Nyquist AC, Gonzales R, Steiner JF, Sande MA. Antibiotic prescribing for children with colds, upper respiratory tract infections, and bronchitis. JAMA. 1998;279:875-877

28. Everard ML. The relationship between respiratory syncytial virus infections and the development of wheezing and asthma in children. Curr Opin Allergy Clin Immunol. 2006;6:56-61

29. Celedon JC, Litonjua AA, Ryan L, Weiss ST, Gold DR. Lack of association between antibiotic use in the first year of life and asthma, allergic rhinitis, or eczema at age 5 years. Am J Respir Crit Care Med. 2002;166:72-75

30. Van Eldere J. The role of bacteria as a local defence mechanism in the ear, nose and throat. Acta Otorhinolaryngol Belg. 2000;54: 243-247

31. McKeever TM, Lewis SA, Smith C, et al. Early exposure to infections and antibiotics and the incidence of allergic disease: a birth cohort study with the West Midlands General Practice Research Database. J Allergy Clin Immunol. 2002;109:43-50 


\section{Early Life Exposure to Antibiotics and the Subsequent Development of Eczema, Wheeze, and Allergic Sensitization in the First 2 Years of Life: The KOALA Birth Cohort Study}

Ischa Kummeling, Foekje F. Stelma, Pieter C. Dagnelie, Bianca E. P. Snijders, John Penders, Machteld Huber, Ronald van Ree, Piet A. van den Brandt and Carel Thijs Pediatrics 2007;119; e225-e231 DOI: $10.1542 /$ peds. $2006-0896$

\section{Updated Information \\ \& Services}

References

Subspecialty Collections

Permissions \& Licensing

Reprints including high-resolution figures, can be found at: http://www.pediatrics.org/cgi/content/full/119/1/e225

This article cites 31 articles, 7 of which you can access for free at:

http://www.pediatrics.org/cgi/content/full/119/1/e225\#BIBL

This article, along with others on similar topics, appears in the following collection(s):

Infectious Disease \& Immunity

http://www.pediatrics.org/cgi/collection/infectious_disease

Information about reproducing this article in parts (figures, tables) or in its entirety can be found online at: http://www.pediatrics.org/misc/Permissions.shtml

Information about ordering reprints can be found online: http://www.pediatrics.org/misc/reprints.shtml 